\title{
Trend of Risk Components among Malaysian Stocks: Evidence from 2008 to 2014
}

\author{
Noor Azuddin Yakob ${ }^{1}$, Stennylaus Duliman ${ }^{1}$, Carl B. McGowan Jr. ${ }^{2}$ \\ ${ }^{1}$ UKM-Graduate School of Business, Universiti Kebangsaan Malaysia, Malaysia \\ ${ }^{2}$ School of Business, Norfolk State University, Norfolk, VA 23507, USA \\ Correspondence: Carl B. McGowan Jr., School of Business, Norfolk State University, Norfolk, VA 23507, USA.
}

Received: November 16, 2015

Accepted: November 30, 2015 Available online: December 16, 2015.

doi:10.11114/aef.v3i1.1252

URL: http://dx.doi.org/10.11114/aef.v3i1.1252

\begin{abstract}
This study examines the nature of risk among Malaysian stocks from January 2008 to July 2014. The paper applies the concept of risk decomposition as stipulated by the single index model (SIM) in which the total risk is partitioned into two main components, i.e. systematic and unsystematic risks. Forty-five companies were randomly selected as the sample for this study. The results show that the unsystematic risk is greater than the systematic risk for all three different time periods used in the study. The level of both types of risk changed over the two sub-periods. The portion of systematic risk has decreased and the unsystematic risk component has increased considerably. This suggests the need for analysts and investors to focus on the company-specific factors when evaluating the risk associated with Malaysian stocks given the greater influence that the unsystematic risk has on total risk.
\end{abstract}

Keywords: Single Index Model, Systematic Risk, Unsystematic Risk, Bursa Malaysia

\section{Introduction}

One of the interesting issues in finance is the relationship between risk and return. It is very common for finance scholars to examine the issue from the perspective of the Capital Asset Pricing Model (CAPM) given the popularity and wide-acceptance of the CAPM. The foundation of the CAPM can be traced to the single index model (SIM). In general, the model relates returns on each security to the returns on a common factor, such as the stock market index that acts as the barometer of the market performance. Returns are determined by the following equation: $R_{i}=\alpha_{i}+\beta_{i} R_{m}+\varepsilon_{i}$ where $R_{i}$, represents the return for stock-i, which can be divided into two components, namely the unique part, i.e. $\alpha_{i}$, and the market-related part, i.e. $\beta_{\mathrm{i}} \mathrm{R}_{\mathrm{m}}$.

The unique part is commonly referred to as the company-specific component as it is associated to micro events that are related to the individual company. The market-related component is normally linked to macro events that affect nearly all stocks in the market. The term beta, i.e. $\beta_{\mathrm{i}}$, is commonly used as the measure of the sensitivity of stock-i to the market movement while $\mathrm{R}_{\mathrm{m}}$ measures the stock market return. In this case, $\varepsilon_{\mathrm{i}}$ is the random firm-specific component of the return, with zero mean and has no relation to $\mathrm{R}_{\mathrm{m}}$.

Within this framework, the SIM proposes that risk for an individual stock can be decomposed into two components, namely the systematic and the unsystematic risks. This concept is simplified by the following formula: $\sigma_{\mathrm{i}}{ }^{2}=\beta_{\mathrm{i}}{ }^{2} \sigma_{\mathrm{m}}{ }^{2}+$ $\sigma_{\mathrm{e}, \mathrm{i}}{ }^{2}$. In short, it says that total risk, i.e. $\sigma_{\mathrm{i}}{ }^{2}$, is derived from the market risk component, i.e. systematic risk $\left(\beta_{\mathrm{i}}{ }^{2} \sigma_{\mathrm{m}}{ }^{2}\right)$, and the unique risk component, i.e. unsystematic risk $\left(\sigma_{\mathrm{e}, \mathrm{i}}{ }^{2}\right)$. Based on this premise, various researchers have conducted numerous studies to examine the nature of the two risk componentsv under many different circumstances.

For example, Hotvedt and Tedder (1978) examined the total risk, systematic risk and unsystematic risk for a group of forest products firms. They found that, in general, the total risks for the five companies are nearly equal. However, the component of systematic risk for the companies varies whereby some companies are found to have a higher systematic risk component than the others. The unsystematic risk component is higher than the systematic risk for all companies. Gopalakrishnan (2014) extended SIM to the information technology companies in India. In his effort to construct the optimal portfolio comprising the companies' stocks, he calculated the variance of the stock returns, betas and the systematic as well as unsystematic risk components. His finding is consistent with that of Hotvedt and Tedder's (1978). Specifically, the unsystematic risk component for all 15 companies is greater than the systematic risk component.

Kim and Gu (2004) examined the impact of the 9/11 terrorist attacks on the return and risk of airline stocks traded on US stock markets. They compared the returns, total risk and systematic risk for these stocks during the 60 weeks before 
and 60 weeks after the $9 / 11$ events. The results show that while the average weekly return of the airline stocks did not change significantly after the $9 / 11$ events, their systematic and total risks increased significantly regardless of firm size. In another study related to the airline industry, Cunningham et al (2004) discovered that the process of carrying out the deregulation of the airline industry has contributed significantly to the increase of the systematic risk for the airline companies

Based on the brief review of the existing literature, it can be inferred that the systematic risk component tends to be greater than the systematic risk component for most companies. These components are time-varying as they do not remain constant all the time. Given these facts, this study seeks to examine the nature of risk components among Malaysian stocks. Considering that the stock market in Malaysia has experienced various episodes of ups and downs, it would be interesting to see if such experience has any bearings on the level of risk among Malaysian stocks.

\section{The Malaysian Stock Market}

The separation of Singapore from Malaysia in 1965 brought a new era of stock trading in Malaysia. Once linked together with trading rooms in Kuala Lumpur and Singapore, the two countries separated in 1973 which lead to the establishment of Kuala Lumpur Stock Exchange. Today the Malaysian stock market is known as Bursa Malaysia and is the only stock exchange that facilitates the stock trading activities in the country. Companies are listed under the Main of the ACE markets. The former is an avenue for fund-raising for established companies while the latter offers an alternative for young companies seeking financial resources. On 18 March 2005, Bursa Malaysia officially became a public company when its stocks were listed on the Main Board.

Companies listed on Bursa Malaysia are classified into 15 sectors based on their principal activities. These sectors are namely consumer products, construction, finance, hotels, industrial products, infrastructure project PLCs, mining, plantations, properties, real estate investment acquisition company (REITs), trading/services, technology, exchange traded funds (ETF), closed-end funds and special purpose acquisition company. As of 2014, over 900 companies were listed on the bourse as shown in Table 1.

The performance of the stock market can be traced from the movement of the FTSE Bursa Malaysia Composite Index (CI) which is the main stock index for Malaysia. Operated jointly by Bursa Malaysia and FTSE, the index is a capitalization-weighted stock market index, composed of the 30 largest companies on the Bursa Malaysia by market capitalization. It was adopted on 6 July 2009, with the opening value taken from the closing value of the old Composite Index on 3 July 2009. Prior to that, the old Composite Index was constructed based on the performance of the top 100 companies as they represent the most liquid equity stocks in the market. The Composite Index has a base value of 100, dated on 1 January 1977. The Composite Index has an average value of 778.60 points from 1977 until 2015 with the all-time high being recorded in May of 2014 at 1887.07. The lowest point is 89.04 which was recorded in April of 1977.

Table 1. Total Number of Companies Listed on Bursa Malaysia

\begin{tabular}{lc}
\hline Main Market & 816 \\
ACE Market & 109 \\
Total & 925 \\
\hline Consumer Products & 134 \\
Industrial Products & 260 \\
Construction & 44 \\
Trading Services & 206 \\
Technology & 93 \\
Infrastructure & 6 \\
SPAV & 2 \\
Finance & 36 \\
Hotel & 4 \\
Properties & 85 \\
Plantations & 38 \\
Mining & 1 \\
REITs & 16 \\
TOTAL & 925 \\
\hline
\end{tabular}

Figure 1 shows the movement of the Composite Index from the year 2000 to 2014. Based on the graph, it shows that the stock market has experienced several market cycles. While in general, the market has been moving on an upward trend since 2000 , there were also a number of incidents of stock market decline notably at the middle of the graph (i.e. 2008 - 
2009). Given the various stages found from the movement of the Composite Index over that period, one can expect that the companies must have also been affected either directly or indirectly. It is therefore necessary to examine the impact of such events on the nature of risk of the stock returns, namely the systematic and unsystematic risks. This study seeks to investigate the relative values of these two types of risk over a six and a-half year period, i.e. from January 2008 to July 2014.

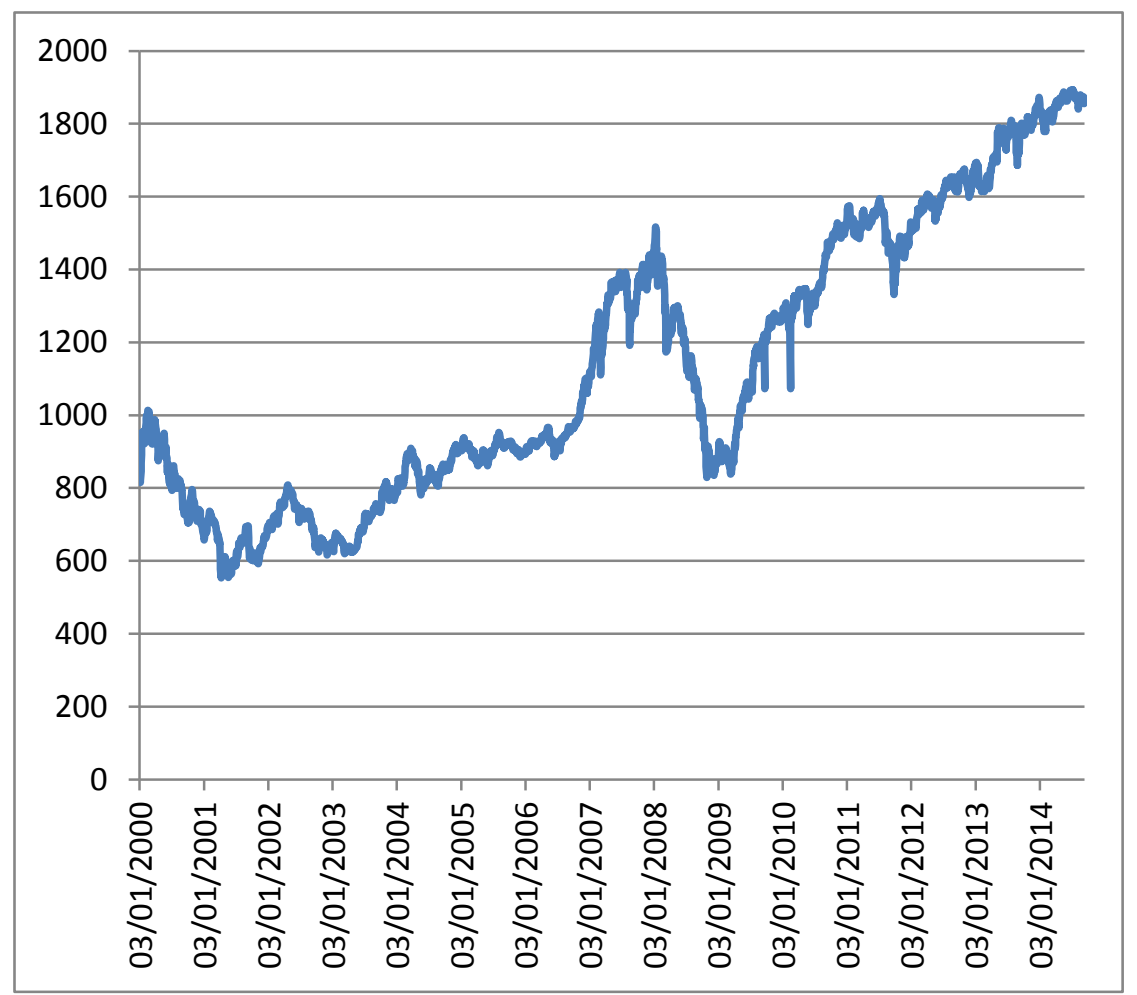

Figure 1. FTSE Bursa Malaysia Composite Index from 2000 to 2014

\section{Data and Methodology}

This study begins by randomly selecting 45 companies that were listed on Bursa Malaysia. The list of the selected companies can be found in Appendix A. The monthly data comprising the closing prices of the 45 companies and the Composite Index of Bursa Malaysia were obtained covering the period of January 2008 to July, 2014. In all, 79 monthly observations were involved for each company and the Composite Index which were then used to calculate the monthly return. The following formula is applied to calculate the monthly return: $R_{t}=\left[\left(\mathrm{P}_{t}-\mathrm{P}_{\mathrm{t}-1}\right) / \mathrm{P}_{t}\right] \times 100 \%$ where $\mathrm{R}_{t}$ represents the monthly return for period $t$ which is computed by taking the difference between the closing prices, i.e. $P$, at period $t$ and t-1. Overall, 46 series of monthly returns were generated with each series containing 78 monthly returns. The series were also being sub-divided into two parts at the mid-point resulting in 39 observations for each part. The idea of partitioning the data set into two sets is to test for the stability of the risk components over the two periods.

Using the series of monthly returns, the variance for each company's monthly return is then estimated. In general, the basic statistical concept is applied to determine the variance whereby $\sigma_{i}^{2}=\sum\left[\left(R_{i, t}-E(R)_{i}\right]^{2} /(N-1)\right.$. In this case, $\sigma_{i}^{2}$ is the variance for the monthly return of company-i which is assumed to represent the total risk. It is found by squaring the difference between each monthly return, i.e. $R_{i, t}$ and the average return for each series, $E(R)_{i}$. The total sum of the squared differences is then divided by $\mathrm{N}-1$ to adjust for the degree of freedom where $\mathrm{N}$ represents the number of observations in the series, i.e. 78. The same process is repeated to calculate the variance for each sub-period where each sub-period consists of 39 observations, i.e. $\mathrm{N}=39$.

The process continues by estimating the beta for each company. Based on the single index model (SIM), beta is a proxy for the systematic risk which represents the slope of the characteristic line that describes the relationship between the company's and the stock market returns. In this case, the stock market return is determined by finding the monthly return of the Composite Index using the same procedure described earlier. To estimate beta, the covariance between each company's returns and the index's returns is computed before being divided by the market variance. This process can be described by the following formula: $\beta_{\mathrm{i}}=\operatorname{Cov}_{\mathrm{i}, \mathrm{m}} / \sigma_{\mathrm{m}}{ }^{2}$. The covariance, i.e. $\operatorname{Cov}_{\mathrm{i}, \mathrm{m}}$, is first determined by applying the formula $\operatorname{Cov}_{\mathrm{i}, \mathrm{m}}=\sum\left[\left(\mathrm{R}_{\mathrm{i}, \mathrm{t}}-\mathrm{E}(\mathrm{R})_{\mathrm{i}}\right]\left[\left(\mathrm{R}_{\mathrm{m}, \mathrm{t}}-\mathrm{E}(\mathrm{R})_{\mathrm{m}}\right] /(\mathrm{N}-1)\right.\right.$ where the numerator represents the product of the difference between each company's monthly return and the index's while N-1 marks the adjustment for the degree of 
freedom. $\sigma_{\mathrm{m}}{ }^{2}$ represents the market variance.

Once the variance and beta for each company is obtained, the next step is to calculate the component of unsystematic risk for each company. This study adopts the concept that can be found in SIM whereby $\sigma_{\mathrm{i}}{ }^{2}={\beta_{\mathrm{i}}}^{2} \sigma_{\mathrm{m}}{ }^{2}+{\sigma_{\mathrm{e}, \mathrm{i}}}^{2}$. In this context $\sigma_{\mathrm{i}}{ }^{2}$ represents the total risk for company-i, $\beta_{\mathrm{i}}{ }^{2} \sigma_{\mathrm{m}}{ }^{2}$ is the proxy for the systematic risk component while $\sigma_{\mathrm{e}, \mathrm{i}}{ }^{2}$ is assumed to represent the unsystematic risk component. While $\sigma_{\mathrm{i}}{ }^{2}$ and $\beta_{\mathrm{i}}{ }^{2} \sigma_{\mathrm{m}}{ }^{2}$ can be directly estimated using the available data series, $\sigma_{e, i}{ }^{2}$ is found by taking the difference between the total risk and the systematic risk components, i.e. $\sigma_{e, i}{ }^{2}=\sigma_{i}{ }^{2}-\beta_{i}{ }^{2} \sigma_{m}{ }^{2}$. Based on the findings from this study, the pattern of risk components for the companies concerned can be established. To test for the stability of the risk components over the two sub-periods, the t-test to compare the means between the two sub-periods is performed.

\section{Findings and Implications}

Panel A in Table 2 below summarizes the descriptive statistics of the calculated variance and beta. The statistics represent the variance and beta for the overall period as well as for sub-periods 1 and 2 . The average variance for the 45 companies is 0.00529 . It was found that the variance for sub-period 1 is higher than the mean (i.e. 0.00706) while the variance for sub-period 2 is lower than the average variance (i.e. 0.00359). This finding indicates that the level of variance is time-varying and over the six and one-half year period under study, the variance is lower for the second time period. This is confirmed by the range between the highest and the lowest values of variance reported during these periodsc. For sub-period 1, the range is 0.02079 (i.e. $0.02109-0.0030$ ) while the range for sub-period 2 is 0.01665 (i.e. $0.01739-0.00074)$. The range for the overall period is 0.01404 . The narrower range found in sub-period 2 suggests the improvement in the volatility of variance, thus indicating that the market may have been more stable in the recent years.

The beta for the overall period is 0.96547 and it is found to be almost similar to that of sub-periods 1 and 2 (i.e. 0.97068 and 0.95455 ). Given that the average value of beta for all the 45 companies is found to be less than 1, it suggests that the companies' stock is less volatile than the market movement. Appendix A lists the beta of the three series and with the exception of Ann Joo Corporation Berhad whose beta for the overall period was found to be 2.32, other companies' beta was within the range of 1 . Nonetheless, the betas for the two sub-periods were not stable as they change in value over the two periods. 23 companies have a higher beta in sub-period 1 than in sub-period 2 while the other 22 companies have their beta increased over that period. Such finding indicates the instability of beta and this can be attributed to the different timeframe used to estimate beta.

Table 2. Descriptive Statistics

Panel A:

\begin{tabular}{ccccccc}
\hline & variance & variance1 & variance2 & beta & beta1 & beta2 \\
\hline Minimum & 0.00137 & 0.00030 & 0.00074 & 0.12747 & -0.07339 & -0.03940 \\
Maximum & 0.01541 & 0.02109 & 0.01739 & 2.32004 & 2.57787 & 1.85742 \\
Mean & 0.00529 & 0.00706 & 0.00359 & 0.96547 & 0.97068 & 0.95455 \\
Std. & & & & & & \\
Deviation & 0.00324 & 0.00503 & 0.00284 & 0.47815 & 0.57339 & 0.41628 \\
\hline Panel B: & & & & & & \\
\hline & systematic & systematic1 & systematic2 & unsystematic & unsystematic1 & unsystematic2 \\
\hline Minimum & 0.00002 & 0.00000 & 0.00000 & 0.00134 & 0.00028 & 0.00030 \\
Maximum & 0.00820 & 0.01571 & 0.00249 & 0.01081 & 0.01639 & 0.01490 \\
Mean & 0.00176 & 0.00299 & 0.00078 & 0.00353 & 0.00407 & 0.00281 \\
Std. & & & & & & \\
Deviation & 0.00157 & 0.00292 & 0.00058 & 0.00217 & 0.00314 & 0.00249 \\
\hline
\end{tabular}

The summary for the descriptive statistics of the systematic and unsystematic risk components is presented in Panel B of Table 2. The average systematic risk for the 45 companies over the six and a-half year period is 0.00176 . The values for sub-periods 1 and 2 are 0.00299 and 0.00078 respectively. For the unsystematic risk component, the average value is 0.00353 while for sub-periods 1 and 2 are 0.00407 and 0.00281 . For both components, the average value is higher in sub-period 1 than 2, consistent with the finding for the variance. The standard deviation for all variables, i.e. variance, beta, systematic risk and unsystematic risk, confirm the fact that the values are higher in sub-period 1 than in sub-period 2. This is further enhanced by the result of between sub-periods mean test as shown in Table 3 . With the exception of beta, which was found to be not statistically different over the two periods, the variance, systematic and unsystematic 
risks are confirmed to be statistically different at 5 percent level. This shows that in general, the level of risk for the sample companies has improved over time.

Table 3. Test of equal mean between sub-periods.

\begin{tabular}{ccccc}
\hline & Mean Diff & Std Dev & $\mathrm{t}$ & Sig(2-tailed) \\
\hline variance1 - variance2 & 0.0035 & 0.0049 & 4.7430 & 0.0000 \\
systematic1 - systematic2 & 0.0022 & 0.0027 & 5.4381 & 0.0000 \\
unsystematic1 - unsystematic2 & & & & \\
slope1 - slope2 & 0.0013 & 0.0036 & 2.3264 & 0.0247 \\
\hline
\end{tabular}

A further inspection of the components of risk shows that the total risk for the sample stocks was being dominated by the unsystematic risk. As shown in Table 4, almost 66.75 percent of the total risk for the overall period was represented by the unsystematic risk while the remaining 33.25 percent belongs to the systematic component. The same trend is also found for the two sub-periods whereby the component of systematic risk is smaller than that of the unsystematic risk. For sub-period 1, the former registered 42.31 percent while the later was found to be 57.69 percent. Despite maintaining the same trend in sub-period 2, the portion of systematic risk has dropped to 21.68 percent as compared to the unsystematic risk which grew to 78.32 percent. This finding suggests that the risk of Malaysia stocks is very much influenced by the company specific factors rather than market related factors. This is very much so in the later part of the timeframe (i.e. mid-2011 onwards) where the unsystematic risk component has become so overwhelming that it makes up almost 80 percent of the total risk.

Table 4. The systematic and unsystematic risk components in percentage.

\begin{tabular}{ccc}
\hline Percentage: & Systematic(\%) & Unsystematic (\%) \\
\hline overall & 33.25 & 66.75 \\
subperiod1 & 42.31 & 57.69 \\
subperiod2 & 21.68 & 78.32 \\
\hline
\end{tabular}

The dominance of the unsystematic risk can also be seen at the individual company level. As summarized in Table 5, the number of companies with the unsystematic risk exceeding the systematic risk is higher than the other way round. For the overall period, 39 (i.e. 86.7\%) of the companies carry higher unsystematic risk component as opposed to the systematic risk and only 6 companies (i.e. 13.3\%) have their systematic risk component higher that the unsystematic risk. The trend is consistent for the two sub-periods too. However, the number of companies for each category is not consistent. The number of companies with higher systematic risk component has dropped from 11 (i.e. $24.4 \%$ ) in sub-period 1 to only 2 (i.e. $4.4 \%$ ) in sub-period 2. On the other hand, although only 34 companies (i.e. $75.6 \%$ ) of the companies found to have higher level of unsystematic risk in sub-period 1, the number has increased to 43 (i.e. $95.6 \%$ ) in sub-period 2. This is an interesting finding which supports the earlier result which indicates that Malaysian stocks are now more prone to the company-specific than the market-specific factors.

Table 5. Systematic risk vs. unsystematic risk based on the number of companies.

\begin{tabular}{cccc}
\hline & $\mathrm{S}>\mathrm{U}$ & $\mathrm{S}<\mathrm{U}$ & Total \\
\hline overall & $6(13.3 \%)$ & $39(86.7 \%)$ & $45(100 \%)$ \\
subperiod1 & $11(24.4 \%$ & $34(75.6 \%)$ & $45(100 \%)$ \\
subperiod2 & $2(4.4 \%)$ & $43(95.6 \%)$ & $45(100 \%)$ \\
\hline
\end{tabular}

\section{Conclusion}

This study examines the nature of risk among Malaysian stocks for a six and a-half year period starting from January 2008 to July 2014. It applies the concept of risk decomposition as stipulated by the single index model (SIM) in which the total risk is partitioned into two main components, i.e. systematic and unsystematic risks. 45 companies were randomly selected as the sample for this study. The results show that the unsystematic risk is greater than the systematic risk for all three different time frames used in the study. This suggests the need for analysts and investors to focus on the company-specific factors when evaluating the risk associated to Malaysian stocks given the great influence that the unsystematic risk have towards total risk. Such finding also poses a great challenge to fund managers in forming portfolios that can diversify away the unsystematic risk since it makes up a big part of the total risk.

The level of both types of risk has also changed over the two sub-periods. The portion of systematic risk has shrunk while the unsystematic risk component has increased considerably. This is confirmed by the majority of the companies that manifested the pattern. The overwhelming dominance of unsystematic risk implies the susceptibility of Malaysia 
stocks to factors peculiar to the company. This could explain the low price placed by investors on some Malaysian companies such as Malaysia Airlines. Despite once being the giant in the Malaysian aviation industry, the stock price has even dropped to 19 sen per share in July 2014 before eventually being delisted from Bursa Malaysia. Perhaps the investing public has now become more sensitive towards company-specific issues which influence their pricing decision. On this note, the management of the company must send the right signals to the public so that their companies' stocks will not be subject to speculation which can add to the unnecessary volatility of the stock price.

\section{References}

Cunningham, L. F., Slovin, M.B., Wood, W. R., \& Zaima, J. K. (1988). Systematic Risk in the Deregulated Airline Industry, Journal of Transport Economics and Policy, 22(3), 345-353.

Gopalakrishnan, M. M. (2014). Optimal Portfolio Selection Using Sharpe's Single Index Model, Indian Journal of Applied Research, 4(1), 286-288

Haugen, R. A. (2001). Modern Portfolio Theory: 5th Edition, Prentice-Hall, Inc., Upper Saddle River, New Jersey.

Hotvedt, J. E., \& Tedder, P. L. (1978). Systematic and Unsystematic risk of Rates of Returns Associated with Selected Forest Products Companies, Southern Journal of Agricultural Economics, 10, 135-138.

Kim, H., \& Gu, Z. (2004). Impact of the 9/11 terrorist attacks on the return and risk of airline stocks, Tourism and Hospitality Research, 5, 150-163. 
APPENDIX A

\begin{tabular}{|c|c|c|c|c|}
\hline Company & Beta & Beta1 & Beta2 & \\
\hline 1. Affin Holdings Berhad & 1.35 & 1.31 & 1.47 & \\
\hline 2. Alliance Financial Berhad & 1.23 & 1.38 & 0.72 & $*$ \\
\hline 3. AMMB Holdings Berhad & 1.31 & 1.52 & 0.67 & $*$ \\
\hline 4. Ann Joo Corporation Berhad & 2.32 & 2.58 & 1.51 & $*$ \\
\hline 5. BAT Berhad & 0.30 & 0.04 & 1.16 & \\
\hline 6. Batu Kawan Berhad & 0.70 & 0.74 & 0.61 & $*$ \\
\hline 7. Bousted Berhad & 1.27 & 1.37 & 0.95 & $*$ \\
\hline 8. Carlsberg Berhad & 0.90 & 0.72 & 1.49 & \\
\hline 9. CIMB Berhad & 1.38 & 1.33 & 1.55 & \\
\hline 10. Dialog Berhad & 1.42 & 1.42 & 1.44 & \\
\hline 11. Digi.com Berhad & 0.61 & 0.57 & 0.75 & \\
\hline 12. DRB-Hicom Berhad & 1.67 & 1.73 & 1.49 & $*$ \\
\hline 13. Fraser and Neave Berhad & 0.32 & 0.23 & 0.66 & \\
\hline 14. Gamuda Berhad & 1.66 & 1.66 & 1.65 & $*$ \\
\hline 15. Genting Berhad & 1.29 & 1.39 & 1.01 & $*$ \\
\hline 16. Genting Plantation Berhad & 1.30 & 1.42 & 0.91 & $*$ \\
\hline 17. Guinness Berhad & 0.55 & 0.34 & 1.25 & \\
\hline 18. HL Financial Group Berhad & 0.77 & 0.74 & 0.88 & \\
\hline 19. Hong Leong Berhad & 0.57 & 0.44 & 1.03 & \\
\hline 20. IGB Corporation Berhad & 1.18 & 1.23 & 1.00 & $*$ \\
\hline 21. IJM Corporation Berhad & 1.52 & 1.68 & 1.01 & $*$ \\
\hline 22. IOI Berhad & 1.30 & 1.40 & 0.98 & $*$ \\
\hline 23. KL Kepong Berhad & 0.89 & 1.03 & 0.42 & $*$ \\
\hline 24. LaFarge Berhad & 1.11 & 1.19 & 0.89 & $*$ \\
\hline 25. Malaysia Airport Berhad & 1.09 & 1.08 & 1.15 & \\
\hline 26. Maybank Berhad & 1.12 & 1.25 & 0.71 & $*$ \\
\hline 27. MMC Corporation Berhad & 0.46 & 0.30 & 1.00 & \\
\hline 28. MISC Berhad & 1.22 & 1.40 & 0.62 & $*$ \\
\hline 29. Nestle Berhad & 0.30 & 0.16 & 0.77 & \\
\hline 30. Oriental Holdings Berhad & 0.78 & 0.64 & 1.22 & \\
\hline 31. Parkson Berhad & 0.93 & 1.23 & -0.04 & $*$ \\
\hline 32. Petronas Dagangan Berhad & 0.37 & 0.34 & 0.51 & \\
\hline 33. Petronas Gas Berhad & 0.33 & 0.09 & 1.09 & \\
\hline 34. PPB Group Berhad & 0.93 & 1.00 & 0.74 & $*$ \\
\hline 35. Press Metal Berhad & 1.74 & 1.70 & 1.86 & \\
\hline 36. RHB Capital Berhad & 1.31 & 1.31 & 1.34 & \\
\hline 37. Shell Refining Berhad & 0.15 & 0.22 & -0.03 & $*$ \\
\hline 38. Sime Darby Berhad & 1.03 & 1.10 & 0.78 & $*$ \\
\hline 39. SP Setia Berhad & 1.23 & 1.45 & 0.56 & $*$ \\
\hline 40. Telekom Berhad & 0.13 & -0.07 & 0.75 & \\
\hline 41. Tenaga Nasional Berhad & 1.00 & 0.89 & 1.37 & \\
\hline 42. UMW Holdings Berhad & 0.55 & 0.59 & 0.43 & $*$ \\
\hline 43. United Plantation Berhad & 0.68 & 0.76 & 0.41 & $*$ \\
\hline 44. YTL Corporation Berhad & 0.54 & 0.31 & 1.27 & \\
\hline 45. YTL Power Berhad & 0.59 & 0.49 & 0.95 & \\
\hline
\end{tabular}

Note: * marks $\beta_{1}>\beta_{2}$.

\section{(cc) EY}

This work is licensed under a Creative Commons Attribution 3.0 License. 